Revista Bioética

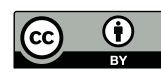

Print version ISSN 1983-8042 On-line version ISSN 1983-8034

Rev. Bioét. vol.28 no.4 Brasília Out./Dez. 2020

Doi: 10.1590/1983-80422020284426

\title{
ATUALIZAÇÃo
}

\section{(Bio)ética e população em situação de rua: entre Agamben e Derrida}

Fernanda Gomes Faria ${ }^{1}$, Rodrigo Siqueira-Batista ${ }^{2}$

1. Universidade Federal Fluminense, Niterói/RJ, Brasil. 2. Universidade Federal de Viçosa, Viçosa/MG, Brasil.

\section{Resumo}

Neste artigo pretende-se analisar problemas bioéticos relativos às populações em situação de rua a partir dos conceitos de homo sacer, de Giorgio Agamben, e de hospitalidade incondicional, de Jacques Derrida. Como elementos-chave destacam-se a invisibilidade dessas populações e o reconhecimento de que profissionais e instituições de saúde devem operar em lógica de cultura hospitaleira, que considere o cuidado às pessoas em situação de rua como significativa ação ética.

Palavras-chave: Atenção primária à saúde. Ética. Pessoas em situação de rua.

\section{Resumen}

\section{(Bio)ética y personas sin hogar: entre Agamben y Derrida}

En este artículo, se pretende analizar los problemas bioéticos relativos a las personas sin hogar con base en los conceptos de homo sacer, de Giorgio Agamben, y hospitalidad incondicional, de Jacques Derrida. Como elementos clave se destacan la invisibilidad de dichas poblaciones y el reconocimiento de que los profesionales e instituciones de salud deben operar en una lógica de la cultura hospitalaria, que tenga en cuenta el cuidado a las personas sin hogar como significativa acción ética.

Palabras clave: Atención primaria de salud. Ética. Personas sin hogar.

\section{Abstract \\ (Bio)ethics and homeless persons: between Agamben and Derrida}

This article aims to analyze bioethical issues related to homeless persons based on the concepts of homo sacer, by Giorgio Agamben, and unconditional hospitality, by Jacques Derrida. We considered the following key elements: the invisibility of these people and the recognition that health professionals and institutions must operate within the logic of a hospitable culture, considering care for this population as a significant ethical action.

Keywords: Primary health care. Ethics. Homeless persons. 
Os sentidos atribuídos à população em situação de rua (PSR) - em termos de sua constituição, determinações, fluxos e derivações - dependem do aprofundamento das análises sobre o fenômeno, tendo como pano de fundo o processo de exclusão social no Brasil. Essa concepção, que inter-relaciona o tema com a questão da pobreza e da desigualdade, considera a instabilidade do lugar social do sujeito em situação de rua, a qual interfere diretamente em suas condições de saúde ${ }^{1}$.

Em última análise, o que está em jogo é a lógica neoliberal inscrita no âmago do capitalismo tardio, pautada na perspectiva de: 1) expandir corporações multinacionais e maximizar fluxos internacionais de capital; 2) globalizar mercados; 3) encolher o controle estatal na economia; 4) dilapidar recursos naturais; 5) desmontar o estado de bem-estar social; 6) valorizar o individualismo; e 7) estimular a competitividade desenfreada ${ }^{2-4}$, como demonstrado no filme $A$ cabana (Die Summe meiner einzelnen Teile, no original), de Hans Weingartner ${ }^{5}$. Emerge, então, processo ambíguo de captura/exclusão que alcança uma parcela da sociedade, lançando os sujeitos à própria sorte, expropriando-os da dialética produção/consumo e os transformando em PSR.

Nesse sentido, os muitos modos de existência da PSR estão marcados pela violação de seus direitos humanos fundamentais, pela flagrante desigualdade econômica e social e pela distância das políticas públicas. Também são produzidos discursos criminalizantes que reafirmam distintos estigmas sobre essa população: os "vagabundos", os que "não querem trabalhar", os "marginais", entre outras alcunhas pejorativas $^{6}$. Há, com efeito, notável recorrência nas formas de exclusão às quais a PSR está submetida ${ }^{7}$.

Dessa forma, reconhecendo o (não) lugar social atribuído à PSR e a negação de direitos, as violências e as barreiras às quais está submetida, é importante formular teoricamente o problema, de modo a buscar referenciais para caracterizá-lo e discutir alternativas para sua condução. Deste modo, o objetivo deste artigo é discutir a PSR com base nos conceitos de homo sacer - de Giorgio Agamben ${ }^{8}-$ e de hospitalidade incondicional - de Jacques Derrida $^{9}-$, os quais poderão trazer novas chaves para a apreciação teórica do problema, em termos (bio)ético-políticos, quiçá com vistas a propor ações no âmbito da práxis de cuidado às pessoas.

\section{A concepção de homo sacer e as populações em situação de rua}

O conceito de homo sacer diz respeito à figura do direito romano arcaico que abrange aquele que cometeu determinado crime para o qual não há punição prevista, tornando-se "indesejado" tanto no âmbito humano quanto divino. De fato, trata-se de alguém que não poderá ser submetido a rituais de punição (sacrifício). Lançado à própria sorte - além da "justiça humana" e aquém da "justiça divina", talvez situado em um limbo inscrito entre ambas pode ser morto sem que tal ato seja tipificado como crime. Ou seja, o homo sacer é excluído da esfera de ser sacrificado - quesito de insacrificabilidade - mas capturado pela possibilidade de ser morto - quesito da matabilidade ${ }^{8}$. Sua vida, exposta ao abandono por deuses e homens, à mercê de um poder de morte, é "insacrificável", mas "matável" 6 .

De um lado há a sacralidade e a autoridade dos que detêm o poder; de outro, a matabilidade e a insacrificabilidade do homo sacer, sobre quem todos os homens agem como soberanos. Esse sujeito, que se encontra ao mesmo tempo preso e exposto à violência, está submetido à dupla subtração - reflexo da exclusão política-de seus direitos humanos e divinos ${ }^{8}$.

É possível relacionar o conceito de Agamben à vida das pessoas em situação de rua ${ }^{10}$. De fato, a submissão à sociedade civil e ao Estado sujeita a PSR a todo tipo de violência e descaso, institucional ou não, com diversas repercussões individuais e coletivas. Sua existência - como a do homo sacer é separada de seu contexto e, sobrevivendo por assim dizer à morte, é por isto incompativel com o mundo humano ${ }^{11}$. Abandonadas à própria vulnerabilidade, as pessoas em situação de rua experimentam a fragilidade de uma vida nua ${ }^{8}$.

Considerados sem autonomia, submetidos à realidade violenta de que fazem parte, sem possibilidade de buscar caminhos diferentes para ultrapassá-la, estes sujeitos apenas resistem e na tentativa de continuarem vivos levam a vida que podem, apesar de mantê-la numa irregularidade que alimenta e sustenta certa lógica de governo que não cessa em condená-la como um mal para as cidades $^{12}$. Considerando esse abandono estrutural e subjetivo, identifica-se relação de inclusão excludente, pois o indivíduo que foi posto em bando é remetido à própria separação e, juntamente, entregue à mercê de quem o abandona, ao mesmo tempo excluso $e$ incluso, dispensado e, simultaneamente, capturado ${ }^{13}$.

Por meio de práticas coercitivas, o poder regula, tutela, transforma e mantém a pessoa em situação de rua na fronteira, em circunstância-limite, a qual engendra uma zona de indistinção entre dentro e fora. Esse sujeito supostamente faz parte da sociedade, mas ao mesmo tempo carece de noção clara de pertencimento nas relações e no cotidiano ${ }^{6}$. 
Trata-se de situação análoga à do homo sacer, cuja existência, visto que qualquer um pode matá-lo sem cometer homicídio, (...) é reduzida a uma vida nua despojada de todo direito, que ele pode somente salvar em uma perpétua fuga ou evadindo-se em um país estrangeiro. Contudo, justamente por ser exposto a todo instante a uma incondicionada ameaça de morte, ele encontra-se em perene relação com o poder que o baniu. Ele é pura zoé, mas a sua zoé é capturada como tal no bando soberano e deve a cada momento ajustar contas com este, encontrar o modo de esquivá-lo ou de enganá-lo. Neste sentido, como o sabem os exilados e os banidos, nenhuma vida é mais política do que a sua ${ }^{14}$.

O sujeito que está em situação de rua pode ser identificado como homo sacer, pois está excluído de benefícios sociais e submetido a constantes atos de violência. Sua vida é exposta, descartável, e pode ser tirada por qualquer um, muitas vezes sem punição, vide as recorrentes chacinas e assassinatos que vitimam essas pessoas e que, em geral, passam impunes ${ }^{15}$. Seus corpos são violentados centenas de vezes, sem qualquer chance de defesa ou de resposta ${ }^{16}$.

Excluídas socialmente, mas ao mesmo tempo capturadas pelo sistema, as vidas constituintes da PSR podem ser vigiadas, recolhidas e, eventualmente, exterminadas, como aponta Agamben ${ }^{8}$. Ademais, como mostra Butler, há formas de distribuir a vulnerabilidade, diferentes maneiras de alocá-la que fazem com que algumas populações sejam mais sujeitas à violência arbitrária do que outras ${ }^{17}$. A impunidade é também fruto da exclusão, da marginalização e da opressão escancarada nas ruas, nos becos e nas vielas das cidades, apontando para existências descartáveis, ou seja, que não importam. Supostamente, essas vidas podem ser eliminadas pelo incômodo que geram ao revelar a miséria que constrange a sociedade e o poder público, por sua simples existência política, à mercê da relação com o poder que as baniu. Trata-se de uma vida absolutamente matável, objeto de uma violência que excede tanto a esfera do direito quanto a do sacrifício ${ }^{18}$. Com efeito, delineia-se - à guisa de exemplo - tal aproximação entre a figura do homo sacer e a pessoa em situação de rua a partir de uma das muitas notícias que expressam a matabilidade e descartabilidade dessa população:

Ataques a moradores de rua no país costumam seguir um mesmo padrão. São feitos de madrugada, sem a possibilidade de defesa e de identificação dos agressores e são, em geral, com armas de fogo. Além dessas características, todos são marcados pela impunidade. Levantamento feito pela Folha mostra que cinco dos principais ataques dos últimos cinco anos não tiveram um desfecho: ninguém está preso nem foi condenado pelos crimes ${ }^{19}$.

Os assassinatos estão imbuídos da neutralidade baseada na soberania de quem detém o poder sobre a vida do homo sacer, a qual pode ser descartada simbolicamente - pelas privações, estigmatizações e demais violências - ou concretamente, como nas chacinas e intervenções higienistas legitimadas por iniciativa pública. Um exemplo dessas ações aconteceu no Rio de Janeiro, em agosto de 2017:

Um dos mais evidentes problemas sociais do Rio está nas calçadas, coberto por trapos e pedaços de papelão, à vista de qualquer um. Mas nem todos querem ver, muito menos de perto. Até mesmo as autoridades têm fechado os olhos. Assim como o Edifício Roxy, em Copacabana, que instalou uma espécie de chuveirinho na marquise, outros prédios têm adotado estratégias para afastar moradores de ruas. Arame farpado, tapumes, grades, creolina, ameaças e agressões são alguns dos "métodos" usados por comerciantes e condôminos para evitar que adultos, jovens e crianças durmam em suas portas. Enquanto a população de rua cresce são 14.279 em toda cidade -, a prefeitura ainda estuda o que fazer para superar esse desafio ${ }^{20}$.

A população em situação de rua é cotidianamente expulsa de seus locais de estadia por esses "métodos", que justificam a recorrente fuga, evasão e itinerância. Nesse contexto, o papel do Estado adquire contornos que passam do foco nos direitos humanos ao discurso da segurança. Assim, ao invés de serem percebidos como ameaçados por dispositivos institucionalizados, os moradores de rua são vistos como ameaça à ordem pública ${ }^{21}$. De fato, o sujeito em situação de rua, tal qual o homo sacer, sofre injúrias e incondicional sujeição a um poder de morte $^{8}$, mesmo tendo estatuto jurídico de cidadão ${ }^{22}$. A ausência de garantia dos direitos básicos perpassa as diferentes vulnerabilidades às quais a PSR está exposta, dentre elas a condição de saúde-doença. Demandas que deveriam fazer parte da constituição e do reconhecimento do sujeito sobre seu próprio corpo são predeterminadas, no caso de sujeitos "matáveis", pela soberania do poder e da Justiça.

Seguindo essa linha, pode-se propor a existência de em um homo doentis brasileiro. Um homem doente que, por sua irracionalidade pressuposta, justifica toda e qualquer forma de tratamento. O morador de rua é transformado em um corpo doente sobre o qual toda e qualquer terapêutica justifica-se. A gestão da sua vida e de seu corpo tem justificativa legitimada 
pelo seu estado de adoecimento pressuposto. As discussões não estão no que se faz, mas nas estratégias relativas às possibilidades de fazer. Os planejamentos das ações de saúde coletiva são tratados em terrenos em que o homem de rua não está: na ciência ou no gabinete de governo. $O$ que lhe é oferecido deve ser adequado por pressuposto e seu saber pode ser legitimamente desconsiderado (...) Dessa maneira, o homo doentis é tratável por todos e por qualquer um, e, portanto, a questão é saber como acessá-lo para que isso se dê. Constituinte de seu ser, a doença o define e justifica a dispensabilidade da escuta de sua racionalidade. A doença é, portanto, a instituição do homem de rua ${ }^{23}$.

Por estar marginalizada, a pessoa em situação de rua - redimensionada como homo doentis ${ }^{15}$ - está submetida às demandas e às ações que os detentores do saber e do poder julgam necessárias. Profissionais, academia e instituições classificam-na apenas por aquilo a que está exposta: suas feridas, sua fome, sua miséria e sua doença ${ }^{24}$. Nessa perspectiva, o próprio corpo do homo sacer, na sua matável insacrificabilidade, é o penhor vivo da sua sujeição a um poder de morte, que não é porém o cumprimento de um voto, mas absoluta e incondicionada ${ }^{25}$. Ou seja, em seu corpo está expresso o poder absoluto que determina a sua não existência, a incondicionada submissão à morte e à privação de seus direitos, sua não autonomia ${ }^{8}$. A produção da vida, da saúde, do sentido e do desejo dessas pessoas é colocada em segundo plano, atropelada principalmente pelas normas e protocolos que sustentam as instituições.

A associação teórica com as reflexões de Agamben ${ }^{8}$ permite explicitar o modo pelo qual a sociedade busca suprimir o incômodo que a PSR gera, desconsiderando maneiras diferentes de existir fora do padrão de uma vida "bem-sucedida". Essa visão expõe os indivíduos que habitam as ruas a um ciclo de busca de sobrevivência que os marca mais por seus desvios do que por aquilo que lhes confere cidadania. Isso se deve ao fato de estarem onde supostamente não deveriam, de serem quem não poderiam, e a despeito disso se produzirem como sujeitos políticos da cidade, ainda que pela "ilegalidade" aos olhos do status quo ${ }^{6}$. Compondo tal cenário ao pensamento do filósofo italiano, pode se dizer que o que temos hoje diante dos olhos é, de fato, uma vida exposta e como tal a uma violência sem precedentes, mais precisamente nas formas mais profanas e banais ${ }^{26}$.

É inegável que há políticas, leis, dispositivos, projetos e serviços voltados à PSR. A reflexão que aqui se produz não desconsidera a importância dessas ações, pois, de fato, sem elas a invisibilidade dessa população seria ainda maior. Porém, este ensaio procura analisar também intervenções que supostamente aliviam o sofrimento dos sujeitos "vulneráveis", mas que - na prática - podem contribuir para a intensificação das suas dificuldades, especialmente no âmbito do acesso à saúde ${ }^{27}$. Muitas vezes observam-se condutas protocolares, burocratizadas, e falta de integralidade na rede de atenção, expondo os sujeitos, por exemplo, a constantes reencaminhamentos, em dinâmica muito distante do que se espera de um genuíno espaço-tempo de cuidado.

A figura do homo sacer representa bom referencial para aprofundar a discussão acerca de tema tão complexo, qual seja, as condições de existência das PSR, em perspectiva crítica e reflexiva. Desprovido de direitos e de liberdade, a pessoa em situação de rua, assim como o homo sacer, está submetida a um poder que, ao mesmo tempo, abandona e captura - inclui para excluir. Desta feita, conforme Agamben, a vida humana se politiza somente através do abandono a um poder incondicionado de morte ${ }^{28}$.

Há alternativas a tal lógica? Essa é a questão que ora se apresenta. Pensar linhas de fuga - o que pressupõe, em última análise, o reconhecimento de distintos modos de existência - é a proposta da próxima seção.

\section{Cuidado às populações em situação de rua: em busca da hospitalidade incondicional}

O pensamento de Jacques Derrida ${ }^{9}-$ no que concerne à ideia de hospitalidade incondicional - pode colaborar substancialmente para a reflexão-ação dirigida ao cuidado da PSR. Pode-se situar, como ponto de partida, o conceito de "desconstrução", uma das principais contribuições teóricas do autor ${ }^{29}$, a qual denota um pensamento aberto, exposto tanto à vida como à morte, [que] permite um deslocamento do olhar tanto sobre a biopolítica como sobre nossos traumas diante de seus processos e consequências. Pensar a desconstrução é pensar nós hoje ${ }^{30}$.

A partir dessa noção - a qual pretende subverter a lógica das oposições -, Derrida propõe o conceito de hospitalidade incondicional como possibilidade de uma "democracia por vir" ${ }^{31}$. De fato, segundo Meneses, pode-se descrever a "desconstrução" como o acolhimento do acolhimento, bem como a hospitalidade da hospitalidade ${ }^{32}$. Trata-se do acolhimento puro. Com efeito, tal hospitalidade diz respeito à plena exposição do que acolhe à chegada 
daquele que vem sem ter sido convidado. Aquele que acolhe deve deixar as portas abertas para quem chega, incondicionalmente, oferecendo abrigo, um lugar, sem qualquer exigência de reciprocidade ${ }^{9,29}$.

Ao pensar o descaso com a PSR, torna-se explícita a limitação do acesso e do alcance dos seus direitos básicos e a falta de políticas públicas realmente dirigidas ao pensamento/ação acerca do cuidado a esse grupo. Em síntese, os serviços de saúde - e os profissionais que neles atuam - deveriam fornecer integralmente atenção, hospitalidade e amparo a qualquer cidadão, independentemente de sua condição, pois é esta a experiência mesma da hospitalidade, a condição do acolhimento em geral ${ }^{33}$. Assim, a partir da hospitalidade incondicional é possível refletir acerca da PSR para além dos aspectos políticos e legais, denunciando e combatendo as insuficiências da hospitalidade jurídica, estatal e civil ${ }^{34}$. Nesse sentido, Derrida ${ }^{9}$ propõe a figura do "estrangeiro" enquanto ser alheio a determinada linguagem e técnica, forçado a se arriscar em defesa do direito do país que o acolhe ou o expulsa:

Ele deve pedir a hospitalidade numa língua que, por definição, não é a sua, aquela imposta pelo dono da casa, o hospedeiro, o rei, o senhor, o poder, a nação, o Estado, o pai etc. Estes Ihe impõem a tradução em sua própria língua, e esta é a primeira violência. A questão da hospitalidade começa aqui: devemos pedir ao estrangeiro que nos compreenda, que fale nossa língua, em todos os sentidos do termo, em todas as extensões possiveis, antes e a fim de poder acolhê-lo entre nós? ${ }^{35}$

0 estrangeiro é forasteiro da realidade hegemônica, a que aparentemente não pertence, e nesse aspecto pode ser comparado com a pessoa em situação de rua. Ambos estão à margem e são vistos como destoantes da norma social. Isso implica que quando se pensa em acolhimento institucional, baseado na premissa da hospitalidade incondicional, a linguagem dos serviços e dos profissionais tende a ser inacessível a esses indivíduos. Emprega-se, de fato, um "idioma" muitas vezes ininteligível, marcado pelo tecnicismo próprio da área da saúde. $O$ atendimento é realizado amiúde sem considerar aquilo que verdadeiramente identifica o sujeito em sua individualidade, sem levar em conta suas demandas, sua "língua nativa" e seu modo de viver, de ser e de estar no mundo. É bastante questionável, portanto, exigir que a PSR assimile a lógica, o funcionamento e a linguagem dos serviços que deveriam acolhê-la sem precondições.

Outro ponto relevante refere-se ao modo como a pessoa em situação de rua é vista socialmente, e como isso influencia a forma segundo a qual é ou não acolhida, tendo em vista a prática social de estar e viver na rua, que é responsável pela construção de sua identidade ${ }^{36}$ - percebida como negativa, alvo de repulsa da sociedade e das instituições. Tal identidade, originada da tentativa de classificar pessoas ou territórios, serve de justificativa para ações estigmatizantes e arbitrárias ${ }^{37,38}$. Em relação a isso, Derrida ${ }^{9}$ pondera sobre a importância do nome, que atuaria como espécie de privilégio, exclusivo ao estatuto social e familiar, capaz de conferir identidade nominável, de direito, a seu portador. O nome próprio possibilita a hospitalidade, inclusive ao "estrangeiro".

Com efeito, pode-se pensar a PSR como constituída por sujeitos cuja identidade é formulada e distorcida pela sociedade. Eles são chamados não pelo nome próprio, mas por seus estigmas - "marginais", "drogados", "crackudos", "vagabundos", "mendigos" -, o que lhes nega o direito de ser reconhecidos por sua história. Mesmo entre conhecidos, pessoas em situação de rua são comumente chamadas por apelidos ou nomes que não são o de registro. Muitas pessoas que vivem nas ruas, inclusive, não têm mais acesso à própria documentação, ou, em outros termos, preferem o anonimato. Portanto, não se oferece hospitalidade ao que chega anônimo e a qualquer um que não tenha nome próprio, nem patronímico, nem família, nem estatuto social, alguém que logo seria tratado não como estrangeiro, mas como mais um bárbaro ${ }^{39}$. Desde esta perspectiva, de acordo com Assumpção ${ }^{24}$, a estigmatização desses sujeitos determina até a posição social que assumem para as instituições, bloqueando saberes, discursos e práticas e impedindo possíveis intervenções.

Nesse sentido, a hospitalidade se tornaria condicional e, portanto, paradoxal, pois o que a define é seu caráter absoluto. Ela está voltada a esse outro, desconhecido, anônimo, cedendo a ele o fluxo de vir, de chegar - sem exigir reciprocidade, sequer seu nome $^{9}$. Tal reflexão teórica ressalta a importância do acolhimento sem precedentes, no sentido de receber o estrangeiro sem exigências ${ }^{9}$. Como complementa Soares, a hospitalidade, vista pelo prisma da desconstrução, não supõe identidade. Ela se apresenta como um direito moral, como um dever de humanidade devido a outro ser humano. A hospitalidade, quando incondicional, se define pelo deixar vir o outro, pelo acolhimento sem reservas do outro que chega, é um ato de generosidade para com o outro ${ }^{40}$.

Desde esta perspectiva, é possível reconhecer que os serviços de saúde se configuram a partir de exigências que acabam, com frequência, impondo 
barreiras de acesso a uma população sem nome, sem endereço e sem documento. Na maioria das vezes, há pré-requisitos para o atendimento: prontuários eletrônicos e demais regulações no sistema de dados, por exemplo, não admitem o não preenchimento de algumas informações. Ressalta-se, nesse contexto, a importância de reconhecer o outro - PSR - como alguém que demanda incondicional acolhida. Mais ainda, é relevante destacar que o amparo deve ser exercido sem que quaisquer elementos - por exemplo, a existência de um documento de identificação sejam tacitamente tomados como pressupostos ${ }^{31}$. Agir de forma hospitaleira, por consequência, implica que os atendimentos dos serviços buscados pelas pessoas em situação de rua pautem-se na flexibilização das exigências burocráticas, muitas vezes típicas dos sistemas de saúde, fortalecendo o propósito de universalidade dos modelos assistenciais.

A hospitalidade também pressupõe relação entre quem acolhe e quem é acolhido, inclusive ao se pensar em direitos e deveres inferidos. Deste modo, quem acolhe deve proceder em consonância com o próprio saber-fazer - consciente ou não -, criando espaço para que o outro se aproxime, passo essencial para que se compartilhem decisões (por exemplo, terapêuticas). É mister contrapor-se à configuração hierárquica, caracterizada por exigências que põem em risco a multilateralidade que deveria estar envolvida nesse encontro.

A abertura ao outro é complexa, assim como o é a democracia. A alteridade não pode ser reduzida $^{41}$. Como afirma Derrida, existe uma lei paradoxal ou perversiva: ela toca esse constante conluio entre a hospitalidade tradicional, a hospitalidade no sentido corrente, e o poder. Esse conluio é também o poder em sua finitude, a saber, a necessidade, pelo hospedeiro, de escolher, de eleger, de filtrar, de selecionar seus convidados, seus visitantes ou seus hóspedes, aqueles a quem ele decide oferecer asilo, direito de visita ou hospitalidade. Não há hospitalidade, no sentido clássico, sem soberania de si para consigo, mas, como também não há hospitalidade sem finitude, a soberania só pode ser exercida filtrando-se, escolhendo-se, portanto excluindo e praticando-se violência. A injustiça, uma certa injustiça, e mesmo um certo perjúrio logo começam a partir do limiar do direito à hospitalidade ${ }^{42}$.

Assim, não acolher incondicionalmente o outro implica exclusão e violência, principalmente pela influência já citada do que constitui a soberania e o poder, que são os responsáveis, mesmo que indiretamente, por controlar essas relações. Por isso, segundo Fonseca ${ }^{43}$, Derrida aposta no "sim" incondicional, na precedência da alteridade e no primado do estrangeiro sobre a hegemonia do "eu".

Pensando nisso, antes do poder e da hegemonia de quem acolhe está o sim incondicional, na tentativa de escapar das amarras do poder que corrompe a possibilidade da hospitalidade: Digamos sim ao que chega, antes de toda determinação, antes de toda antecipação, antes de toda a identificação, quer se trate ou não de um estrangeiro, de um imigrado ou de um visitante inesperado, quer o que chega seja ou não cidadão de um outro país, um ser humano, animal ou divino, um vivo ou um morto, masculino ou feminino ${ }^{44}$. Acrescenta-se, no contexto desta discussão, quer o que chega é pessoa que vive em situação de rua. A leitura atenta da citação de Derrida ${ }^{9}$ permite interpretar a hospitalidade incondicional como espécie de engajamento, no qual a subjetividade daquele que acolhe é decisiva para o acolhimento absoluto e livre de dívidas.

Tal reflexão pode ser estendida à produção de cuidado no Sistema Único de Saúde, uma vez que o acolhimento é essencial para democratizar o acesso aos seus serviços, reconhecendo a subjetividade e as necessidades de cada um ${ }^{45}$. Na prática, porém, a acolhida do usuário é comumente relacionada à atitude mecânica adotada por alguns profissionais, erroneamente identificada com a simples ação de triagem administrativa ${ }^{46}$. Para além dessa ideia simplista, deve-se valorizar a genuína abertura ao outro, deixando que ele expresse sua singularidade. A hospitalidade, como defendida por Derrida ${ }^{9}$, deve ser incondicional, o que se alinha ao item IV do artigo 7응 da Lei 8.080/1990, cujo texto explicita a igualdade da assistência à saúde, sem preconceitos ou privilégios de qualquer espécie ${ }^{47}$.

No entanto, no cotidiano dos serviços as ações de acolhimento tendem a se vincular ao cumprimento de protocolos, fazendo que a PSR nem sempre tenha suas demandas atendidas. Esses muitos protocolos e fluxogramas rígidos dificultam a abordagem ampliada dos problemas e culminam no excesso de encaminhamentos a serviços especializados, o que intensifica a lógica hegemônica e a fragmentação do cuidado ${ }^{48}$. Esse tipo de situação seria facilmente dissolvido a partir do acolhimento, da receptividade ao outro, do duplo reconhecimento das singularidades de quem acolhe e de quem é acolhido, como proposto pela noção de hospitalidade incondicional. Tesser, Poli Neto e Campos ${ }^{48}$ ainda complementam que o acolhimento deve ser priorizado por área de abrangência e particularidade dos usuários, sublinhando a importância de direcionar o trabalho em equipe para valorizar a discussão de casos de forma conjunta. 
É preciso destacar, ainda, que o conceito de hospitalidade não é estático, é, de preferência, um conceito dinâmico, que nos obriga a sair de nós próprios e das instituições, para poder estar atento à vulnerabilidade do estrangeiro ${ }^{49}$. Com efeito, na relação entre o serviço e as ruas há não só a hospitalidade do profissional para com o usuário, mas também a instituição, que se relaciona com o próprio espaço público, com o território e as dinâmicas da PSR. Nesse sentido, Derrida aponta que a hospitalidade significa aqui publicidade do espaço público, e que a hospitalidade da cidade ou a hospitalidade privada são dependentes e controladas pela lei e pela polícia do Estado ${ }^{50}$.

Assim, o autor indica e problematiza as consequências dos "delitos de hospitalidade" e como as relações institucionais de poder detêm o modo ideal designado como incondicional. Essa soberania das cidades é fator relevante para pensar o verdadeiro significado de democracia, na teoria e na prática, na medida em que somos produzidos pela cidade ao mesmo tempo que a produzimos, habitando- $a^{51}$. Ademais, Derrida ${ }^{9}$ propõe que a hospitalidade incondicional é ideal, mas dotada de certa impossibilidade - entenda-se: plena manifestação no plano da realidade -, o que é confirmado pelo funcionamento dos serviços de saúde no encontro com a PSR. É difícil acolher incondicionalmente o outro, sem preconceitos, protocolos ou outras instâncias que criem barreiras à naturalidade do encontro:

Tudo se passa como se a hospitalidade fosse o impossivel: como se a lei da hospitalidade definisse essa própria impossibilidade, como se não se pudesse senão transgredi-la, como se a lei da hospitalidade absoluta, incondicional, hiperbólica, como se o imperativo categórico da hospitalidade exigisse transgredir todas as leis da hospitalidade, a saber, as condições, as normas, os direitos e os deveres que se impõem aos hospedeiros e hospedeiras, aos homens e às mulheres que oferecem e àqueles e àquelas que recebem a acolhida ${ }^{52}$.
$O$ acesso pode e deve ser facilitado por atores importantes para as discussões sobre as condições para acolher e atender a PSR. A ação de associações, federações e movimentos sociais - as quais procuram romper barreiras - é essencial ${ }^{24}$. Ademais, a forma de acolhida está relacionada ao processo reflexivo e crítico direcionado à subjetividade e à existência de quem acolhe e de quem é acolhido. Não se pode, portanto, pensar em preparação para a hospitalidade incondicional que não pressuponha o estar despreparado e disponível ao encontro com o inesperado ${ }^{53}$. Aqueles que estão na "linha de frente" representam a instituição responsável pelo cuidado à saúde, mas são também sujeitos imbuídos de representações sobre si mesmos. Essas pessoas devem estar disponíveis para o encontro consigo e com o outro, considerando seus direitos e deveres condicionados e condicionantes ${ }^{54}$, mas sem que estes sejam critérios para o acolhimento incondicional.

\section{Considerações finais}

Pensar a PSR à luz das concepções de homo sacer, de Giorgio Agamben, e de hospitalidade incondicional, de Jacques Derrida, foi o mote deste artigo. As considerações feitas ao longo do texto permitiram colocar em questão o cuidado às pessoas que vivem nas ruas. Desde essa perspectiva, conclui-se que é possível construir formas de acolhimento baseadas na hospitalidade incondicional, zelando pelo âmbito relacional de quem se estabelece como hospitaleiro, a partir da problematização acerca do "como" e do "quem" se tem acolhido ${ }^{43}$. $O$ aceno (bio)ético que permeia o cuidado à PSR deve ser hospitaleiro e incondicional, permitindo o enfrentamento dos nefastos efeitos da captura/exclusão que transforma as pessoas em homo sacer.

Este ensaio representa atualização de parte da dissertação de mestrado de Fernanda Gomes Faria, intitulada Processos de cuidado à saúde da população em situação de rua: entre o homo sacer e a hospitalidade incondicional, elaborada sob a orientação de Rodrigo Siqueira-Batista e defendida no Programa de Pós-Graduação em Saúde Coletiva da Universidade Federal Fluminense em 2018.

\section{Referências}

1. Siqueira-Batista R, Schramm FR. A saúde entre a iniquidade e a justiça: contribuições da igualdade complexa de Amartya Sen. Ciênc Saúde Coletiva [Internet]. 2005 [acesso 25 jan 2018];10(1):129-42. DOI: 10.1590/S1413-81232005000100020

2. Luz MT. Especificidade da contribuição dos saberes e práticas das ciências sociais e humanas para a saúde. Saúde Soc [Internet]. 2011 [acesso 22 ago 2018];20(1):22-31. DOI: 10.1590/S0104-12902011000100004

3. Vasconcellos C, Puzone V. Estática e dinâmica do capitalismo tardio na teoria crítica. Tempo Soc [Internet]. 2018 [acesso 23 jul 2020];30(3):85-102. DOI: 10.11606/0103-2070.ts.2018.145019 
4. Siqueira-Batista R, Gomes AP, Albuquerque VS, Cavalcanti FOL, Cotta RMM. Educação e competências para o SUS: é possível pensar alternativas à(s) lógica(s) do capitalismo tardio? Ciênc Saúde Coletiva [Internet]. 2013 [acesso 23 jul 2020];18(1):159-70. DOI: 10.1590/S1413-81232013000100017

5. Weingartner $\mathrm{H}$, diretor. A cabana [longa-metragem]. Berlim: Kahuuna Films; 2011.117 min., som, cor.

6. Silva WN, Hüning SM. De morador de rua a criminoso. Athenea Digital [Internet]. 2015 [acesso 15 jun 2017];15(2):141-65. DOI: 10.5565/rev/athenea.1479

7. Jodelet D. Os processos psicossociais da exclusão. In: Sawaia B, organizador. As artimanhas da exclusão: análise psicossocial e ética da desigualdade social. 2a ed. Petrópolis: Vozes; 2001. p. 53-66.

8. Agamben G. Homo sacer: o poder soberano e a vida nua I. Belo Horizonte: Editora UFMG; 2002.

9. Derrida J. Questão do estrangeiro: vinda do estrangeiro. In: Dufourmantelle Anne, organizadora. Anne Dufourmantelle convida Jacques Derrida a falar da hospitalidade. São Paulo: Escuta; 2003. p. 5-66.

10. Rio de Janeiro. Ministério Público. A tutela da população em situação de rua: cartilha de orientação [Internet]. Rio de Janeiro: Centro de Apoio Operacional das Promotorias de Justiça de Tutela Coletiva de Defesa da Cidadania; 2015 [acesso 15 jun 2017]. Disponível: https://bit.ly/2Bofyu7

11. Agambem G. Op. cit. p. 107.

12. Silva WN, Hüning SM. Op. cit. p. 160.

13. Agamben G. Op. cit. p. 116.

14. Agamben G. Op. cit. p. 189.

15. Serrano CEG. Homem de rua, homem doente: a população de rua nos discursos do acolhimento institucional público [tese] [Internet]. São Paulo: Universidade de São Paulo; 2013 [acesso 25 jan 2018]. Disponível: https://bit.ly/2OPYcth

16. Silva WN, Hüning SM. Op. cit. p. 155.

17. Butler J. Precarious life: the powers of mourning and violence. Londres: Verso; 2004. p. 12.

18. Agamben G. Op. cit. p. 58.

19. Reis T, Acayaba C. Ataque a morador de rua fica sem solução. Folha de S. Paulo [Internet]. Cotidiano; 28 set 2008 [acesso 13 nov 2017]. Disponível: https://bit.ly/3fULK7F

20. Ouchana G, Ramalho G. Para afastar morador de rua, prédios no Rio retiram marquise e usam até arame farpado. O Globo [Internet]. Rio; 8 ago 2017 [acesso 18 jan 2018]. Disponível: https://glo.bo/3jxwNdK

21. Valencio N, Pavan BJR, Siena M, Marchezini V. Pessoas em situação de rua no Brasil: estigmatização, desfiliação e desterritorialização. In: Valencia N, organizadora. Sociologia dos desastres: construção, interfaces e perspectivas no Brasil. São Carlos: Rima; 2010. v. 2. p. 53-72.

22. Martinez MM, Pereira LFP, Barbosa AR, Oliveira LMF, Pazzini DP. A produção e a gestão da população de rua: a trajetória de Luciene. Dilemas [Internet]. 2014 [acesso 11 jul 2017];7(4):741-67. Disponível: https://bit.ly/2ZTYO7D

23. Serrano CEG. Op. cit. p. 15.

24. Assumpção ELA. A vida em cenas de uso de crack: ensaio de análise institucional e bioética [tese] [Internet]. Niterói: Universidade Federal Fluminense; 2016 [acesso 25 mar 2018]. Disponível: https://bit.ly/2ORkefa

25. Agamben G. Op. cit. p. 84.

26. Agamben G. Op. cit. p. 95.

27. Pussetti C, Brazzabeni M. Sofrimento social: idiomas da exclusão e políticas do assistencialismo. Etnográfica [Internet]. 2011 [acesso 25 mar 2018];15(3):467-78. DOI: 10.4000/etnografica.1036

28. Agamben G. Op. cit. p. 77.

29. Meneses RDB. Da hospitalidade em Derrida ao acolhimento em saúde [tese] [Internet]. Braga: Universidade Católica Portuguesa; 2012 [acesso 17 jul 2018]. Disponível: https://bit.ly/3eRWH8t

30. Lima D. Não se contam os mortos da mesma maneira em todos os lugares do mundo: aproximações entre autoimunidade e biopoder [Internet]. In: Anais do II Colóquio NUFFC; 2017; Rio de Janeiro. Rio de Janeiro: UFRJ; 2017 [acesso 23 ago 2017]. p. 2. Disponível: https://bit.ly/3eUjlgs

31. Soares VDM. Hospitalidade e democracia por vir a partir de Jacques Derrida. Ens Filos [Internet]. 2010 [acesso 17 ago 2018];(11):162-79. Disponível: https://bit.ly/3jCczPU

32. Meneses RDB. A desconstrução em Jacques Derrida: o que é e o que não é pela estratégia. Universitas Philos [Internet]. 2013 [acesso 17 out 2017];30(60):177-204. p. 202. Disponível: https://bit.ly/3jzMWiU

33. Lobo RH. Para um pensamento úmido: a filosofia a partir de Jacques Derrida [tese]. Rio de Janeiro: Pontifícia Universidade Católica do Rio de Janeiro; 2007. p. 385.

34. Bernardo F. A ética da hospitalidade, segundo J. Derrida, ou o porvir do cosmopolitismo por vir a propósito das cidades-refúgio, re-inventar a cidadania. Rev Filos Coimbra [Internet]. 2002 [acesso 26 jan 2018];(22):421-46. Disponível: https://bit.ly/2EaThRz

35. Derrida J. Op. cit. p. 15

36. Gomes Filho J. Identidade, discurso e poder do morador de rua: a construção de uma utopia através do jornal Aurora da rua [Internet]. In: Anais do III Simpósio Nacional Discurso, Identidade e Sociedade; 14-16 fev 2012; Campinas. Campinas: Unicamp; 2012 [acesso 7 nov 2017]. p. 12. Disponível: https://bit.ly/3m9yhME

37. Araújo PT, Tavares MG. População em situação de rua: identidade social e a dialética da inclusão/exclusão. Cad Grad Ciênc Hum Soc [Internet]. 2015 [acesso 2 jan 2018];2(3):113-31. Disponível: https://bit.ly/3fQcgil

38. Assumpção ELA, Schramm FR. Princípios da clínica na rua e os funcionamentos do crack. Rev. bioét. (Impr.) [Internet]. 2017 [acesso 22 jan 2018];25(3):473-81. Disponível: https://bit.ly/30HME0J 
39. Derrida J. Op. cit. p. 23.

40. Soares VDM. Op. cit. p. 164.

41. Milovic M. Política do messianismo: algumas reflexões sobre Agamben e Derrida. Cad Ética Filos Polít [Internet]. 2009 [acesso 26 nov 2017];1(14):103-21. Disponível: https://bit.ly/2D7lw1K

42. Derrida J. Op. cit. p. 49.

43. Fonseca FFA. A verdade da desconstrução: o horizonte ético do pensamento de Jacques Derrida [dissertação] [Internet]. Fortaleza: Universidade Federal do Ceará; 2008 [acesso 20 ago 2018]. Disponível: https://bit.ly/39rKtSN

44. Derrida J. Op. cit. p. 55.

45. Oliveira ILVAC, Siqueira-Batista R. Estratégia Saúde da Família e o imperativo da vida saudável: capturas biopolíticas e sociedades de controle: ou sobre a crítica de Foucault e Deleuze. Trágica [Internet]. 2018 [acesso 30 nov 2020];11(2):89-104. Disponível: https://bit.ly/37oVh3w

46. Neves CAB, Heckert ALC. Micropolítica do processo de acolhimento em saúde. Estud Pesqui Psicol [Internet]. 2010 [acesso 26 nov 2017];10(1):151-68. Disponível: https://bit.ly/2BslaCx

47. Brasil. Lei no 8.080 , de 19 de setembro de 1990. Dispõe sobre as condições para a promoção, proteção e recuperação da saúde, a organização e o funcionamento dos serviços correspondentes e dá outras providências. Diário Oficial da União [Internet]. Brasília, 20 set 1990 [acesso 28 jul 2020]. Disponível: https://bit.ly/3hKNCAd

48. Tesser CD, Poli Neto P, Campos GWS. Acolhimento e (des)medicalização social: um desafio para as equipes de saúde da família. Ciênc Saúde Coletiva [Internet]. 2010 [acesso 19 jan 2018];15(supl 3):3615-24. DOI: 10.1590/S1413-81232010000900036

49. Meneses RDB. Hospitalidade como desconstrução pela parusia segundo Jacques Derrida. Sapientia [Internet]. 2016 [acesso 27 out 2017];72(239):99-116. p. 100. Disponível: https://bit.ly/2CY1DeN

50. Derrida J. Cosmopolites de tous les pays, encore un effort! Paris: Galilée; 1997. p. 56. Tradução livre.

51. Sarmiento ML, Fonti DO. Bioética urbana: desafíos de un campo emergente. Rev Redbioética [Internet]. 2014 [acesso 30 nov 2020];2(10):110-8. p. 114. Tradução livre. Disponível: https://bit.ly/3mmYdUT

52. Derrida J. Op. cit. 2003. p. 68.

53. Meneses RDB. Op. cit. 2016.

54. Meneses RDB. Op. cit. 2016. p. 101.

\section{Participação dos autores}

Fernanda Gomes Faria redigiu a primeira versão do artigo. O texto foi revisto por Rodrigo Siqueira-Batista.

\section{Correspondência}

Rodrigo Siqueira-Batista - Universidade Federal de Viçosa. Departamento de Medicina e Enfermagem. Av. Peter Henry Rolfs, s/n, Campus Universitário CEP 36570-900. Viçosa/MG, Brasil.

Fernanda Gomes Faria - Mestre - fernanda.gf@live.com

(i) 0000-0002-7791-8501

Rodrigo Siqueira-Batista - Doutor - rsbatista@ufv.br

(iD) $0000-0002-3661-1570$ 